\title{
ANÁLISE DA RESPOSTA TECIDUAL E ATIVIDADE ANTINEUROINFLAMATÓRIA COLÔNICA DO METIL JASMONATO NA RETOCOLITE ULCERATIVA CRÔNICA INDUZIDA POR ÁCIDO TRINITROBENZENOSULFÔNICO EM RATOS
}

\author{
Alefe Luiz Caliani Carrera* \\ Isabela Ferraro Moreno* \\ Jean Carlos Fernando Besson \\ Maria Raquel Marçal Natali ${ }^{*+*}$
}

\begin{abstract}
RESUMO: As doenças inflamatórias intestinais (DIls) são caracterizadas por processo inflamatório crônico, sendo duas principais: Doença de Crohn (DC) e Retocolite Ulcerativa (RCU). Desta forma, produtos naturais surgem como alternativas terapêuticas, sendo o metil jasmonato (MeJA) uma provável alternativa de tratamento, visto suas comprovadas atividades anti-inflamatórias, antiproliferativas e antioxidantes. Tal composto é isolado a partir do óleo essencial de Jasminum grandiflorum. Analisou-se o potencial efeito tecidual e neuroinflamatório do MeJA, na dose de $300 \mathrm{mg} / \mathrm{kg}$, em ratos adultos com colite induzida por ácido trinitrobenzenosulfônico (TNBS). Os animais foram distribuídos em quatro grupos, eutanasiados após o tratamento. Foram utilizados amostras do cólon distal de 20 animais para a obtenção de cortes histológicos transversais. Foram realizadas análises morfométricas das túnicas intestinais, por amostragem de imagens capturadas em microscópio óptico; e o perfil antineuroinflamatório do sistema nervoso entérico pela avaliação microscópica de 30 gânglios localizados nos gânglios mioentéricos por animal em contagem e caracterização de células inflamatórias. Notou-se mimetização eficaz de DII pelo TNBS através da redução de células inflamatórias em gânglios entéricos, principalmente linfócitos e monócitos; efeito regenerativo tecidual nas túnicas submucosa e muscular.
\end{abstract}

PALAVRAS-CHAVE: Doenças inflamatórias intestinais; Jasminum; Mucosa intestinal; Regeneração; Sistema nervoso entérico.

\section{ANALYSIS OF TISSUE RESPONSE AND COLON ANTINEUROINFLAMMATORY ACTIVITY OF METHYL JASMONATE IN CHRONIC ULCERATIVE RECTOCOLITIS INDUCED BY TRINITROBENZENOSULFONIC ACID IN RATS}

\begin{abstract}
Intestine inflammatory diseases (IIDs) are characterized by a chronic inflammatory processes mainly, Crohn Disease (CD) and Ulcerative Rectocolites (URC). Natural products suggest therapeutic alternatives such as methyl jasmonate (MeJA) as a probable alternative treatment, with proven anti-inflammatory, antiproliferative and antioxidant activities. The compound is isolated from the essential oil of Jasminum grandiflorum. Potential tissue and neuro-inflammatory effect of MeJA at $300 \mathrm{mg} / \mathrm{kg}$ in adult rats with colitis was induced by trinitrobenzenosulfonic acid (TNBS). Rats were divided into four groups and euthanized after treatment. Samples of distal colon of 20 animals were employed to obtain transversal histological cuts. Morphometric analyses of intestine tunics were undertaken by samples of images by optic microscope; antineuroinflammatory profile of the enteric nervous system was also undertaken by microscopic evaluation of 30 ganglia in the myoenteric ganglia per animal in counting and characterization of inflammatory cells. Efficient simulation of IID by TNBS was reported by reduction of inflammatory cells in enteric ganglia, especially lymphocytes and monocytes; tissue regenerative effect in the submucus and muscular tunics.
\end{abstract}

KEYWORDS: Intestinal inflammatory diseases; Jasminum; Intestinal mucus; Regeneration; Enteric nervous system.

\footnotetext{
"Discente do curso de Medicina Veterinária, Centro Universitário de Maringá - UNICESUMAR. Bolsista PIC/ICETI UniCesumar, Maringá, PR, Brasil. E-mail: alefe_luiz@hotmail.com

** Docente do curso de Medicina, Centro Universitário de Maringá - UNICESUMAR, Maringá, PR, Brasil.

*** Docente do departamento de Ciências Morfológicas, Universidade Estadual de Maringá - UEM, Maringá, PR, Brasil.
} 


\section{INTRODUÇÃO}

A Doença de Crohn (DC) e a Retocolite Ulcerativa (RCU) são consideradas as principais doenças inflamatórias intestinais em acometimento humano, sendo elas doenças de desordem inflamatória intestinal (SANCHEZ-MUÑOZ, DOMINGUEZ-LOPEZ, YAMAMOTO-FURUSHO, 2008), porém sua etiologia ainda não é completamente elucidada (ARDITE et al., 2000; SANCHEZ-MUÑOZ, DOMINGUEZ-LOPEZ, YAMAMOTO-FURUSHO, 2008). Pela ação direta de fatores genéticos, ambientais e imunológicos contra a flora microbiana simbiótica (DOST et al., 2008; SANCHEZ-MUÑOZ, DOMINGUEZ-LOPEZ, YAMAMOTOFURUSHO, 2008), que promovem inflamação crônica do cólon e reto em decorrência de alterações imunes, a qual gera produção exagerada de mediadores inflamatórios e substâncias oxidantes, causando lesões principalmente na camada mucosa intestinal (SANTOS et al., 2014). Em humanos, Dlls atingem principalmente pessoas entre 15 e 35 anos de idade, e dentre os fatores ambientais predisponentes, podese destacar 0 tabagismo (KANDHARE et al., 2012), sendo os indivíduos acometidos mais predispostos à ocorrência de câncer de cólon e reto (SERIL, 2003; KRISHNAN et al., 2014; MOURA et al., 2015) e também de displasia nos mesmos (SERIL, 2003).

Os macrófagos e as células apresentadoras de antígeno da túnica mucosa são as principais células inflamatórias, sendo responsáveis pela produção em alta escala de novas citocinas inflamatórias que culminam com a piora do quadro clínico, tendo ainda participação de linfócitos $T$ (T auxiliares 1 e 2, e também $T$ citotóxico) infiltrados na mucosa intestinal (FIOCCHI, 1998; SANCHEZ-MUÑOZ, DOMINGUEZLOPEZ, YAMAMOTO-FURUSHO, 2008). A resposta Th1 relaciona-se com a DC, enquanto Th2, com RCU (FIOCCHI, 1998).

Há produção inicial de espécies reativas de oxigênio (ERO) (ARDITE et al., 2000), os quais objetivam causar a morte celular através do estresse oxidativo (EREJUWA, SULAIMAN, WAHAB, 2012). A morte celular se dá pela interação dos radicais livres com a membrana celular lipídica, culminando com sua ruptura (ESMAILY et al., 2009), sendo que estas substâncias ainda promovem quimiotaxia das células inflamatórias, que desencadeiam a produção de citocinas (ARDITE et al., 2000). 0 grau da doença e estado clínico do paciente se dá, principalmente, pelos níveis séricos de TNF- (ARAB et al., 2014), sendo este produzido por neutrófilos, macrófagos e linfócitos, sendo 0 maior responsável pelo estresse oxidativo e pelo desencadeamento de produção de outras citocinas (LIU, WANG, 2011), onde 0 principal dano será a destruição das células epiteliais intestinais (ARAB et al., 2014), gerando inflamação e até úlceras de mucosa (HARTMANN et al., 2012).

Histologicamente, observa-se a formação de infiltrado celular inflamatório de neutrófilos, monócitos e linfócitos, principalmente; ulcerações e edema, que podem atingir não somente a túnica mucosa, mas também as demais que compõem a parede intestinal; redução da produção de muco (FIOCCHI, 1998). 0 principal sinal clínico é a diarréia, tendo como principal causador o mediador IL-1 (MARTín et al., 2004). Tais eventos podem estar associados com a degeneração do Sistema Nervoso Entérico (SNE) (GEBOES, COLLINS, 1998). 0 SNE encontra-se na parede de todo o sistema digestório, sendo responsável pelo peristaltismo, secreções, circulação sanguínea e resposta imune por reflexos neurais. É divido em plexos: mioentérico, mucoso e submucoso (HANSEN, 2003). Como resultado, há: alteração na secreção de substâncias, aumento do peristaltismo, dor, hiperplasia e hipertrofia de células e fibras nervosas, e, em alguns casos, há dilatação dos plexos nervosos (GEBOES, COLLINS, 1998).

0 uso experimental do ácido trinitrobenzenosulfônico (TNBS), diluído em solução alcoólica a 50\%, como forma de mimetizar a ocorrência das Dlls, foi proposto inicialmente por Morris et al. em 1989, apresentando características teciduais semelhantes ao desenvolvimento das doenças inflamatórias intestinais(MORRIS et al., 1989). Já o MeJA foi isolado primeiramente a partir do óleo essencial de Jasminum glandiforum (FAROOQI, BUTT, RAZZAQ, 2012). Como alternativa terapêutica, o MeJA apresenta propriedades anticancerígenas (FINGRUT, 
FLESCHER, 2002; FINGRUT et al., 2005; WANG, BOWMAN, DING, 2007; FAROOQI, BUTT, RAZZAQ, 2012), antioxidante (WANG, BOWMAN, DING, 2007), antinociceptiva (UMUKORO, OLUGBEMIDE, 2011), anti-inflamatória (DANG et al., 2008) e antiparasitária (GOLD et al., 2003; OFER, GOLD, FLESCHER, 2008). Em neoplasmas, o MeJA possui propriedades que inibem hormônios de crescimento tumoral, tendo efeito antiproliferativo (FINGRUT, FLESCHER, 2002; WANG, BOWMAN, DING, 2007; FAROOQI, BUTT, RAZZAQ, 2012) e induz a apoptose de células neoplásicas (FINGRUT, FLESCHER, 2002; FINGRUT et al., 2005; FAR00QI, BUTT, RAZZAQ, 2012), através de atuação diretamente na membrana da mitocôndria celular, onde estudos comprovam sua benéfica ação em leucemia, tumores de próstata e mama, e também de melanoma (FINGRUT et al., 2005).

Considerando-se os efeitos colaterais dos medicamentos usados para tratamento da Dlls, terapias alternativas devem ser analisadas. 0 MeJA, devido às propriedades relatadas, pode ser introduzido na terapêutica. Este estudo tem como objetivo analisar 0 efeito anti-inflamatório e promotor da remodelagem intestinal do MeJA na RCU induzida em ratos.

\section{MATERIAIS E MÉTODOS}

0 presente estudo segue às normas $\mathrm{e}$ recomendações do ColégioBrasileirodeExperimentação Animal (COBEA), e a utilização de animais segundo a metodologia deste foi aprovado pelo Comitê de Ética em Experimentação Animal da Universidade Estadual de Maringá (Parecer 074/2014). Foram utilizados ratos, linhagem Wistar, com intuito de mimetização da inflamação intestinal, tratamento e posterior eutanásia para obtenção de cortes histológicos de cólon distal para confecção de lâminas e análise do perfil neuroinflamatório e da remodelagem tecidual. Foram utilizados 20 animais machos, com noventa dias de idade, mantidos em caixas de polipropileno, quatro animais por caixa e com temperatura controlada de $23^{\circ} \mathrm{C}$ a $25^{\circ} \mathrm{C}$, e ciclos de iluminação de claro e escuro de 12 horas, no biotério setorial do Departamento de Ciências Morfológicas (DCM) - UEM. Os animais receberam ração padronizada e água ad libidum, distribuídos em quatro grupos experimentais:

- Grupo CC: animais controle $(\mathrm{n}=5)$;

- GRUPO CJ: animais que receberam enema de $0,6 \mathrm{ml}$ de solução salina $0,9 \%$ e doses diárias de solução metil jasmonato via gavagem; $(\mathrm{n}=5)$;

- GRUPO TN: animais que receberam enema com solução de $15 \mathrm{mg}$ de TNBS $(0,3 \mathrm{ml})$ dissolvidos em $0,3 \mathrm{ml}$ de etanol a $30 \%$, sem nenhuma forma de tratamento; $(n=5)$;

- GRUPO TJ: animais que receberam enema com solução de $15 \mathrm{mg}$ de TNBS (0,3 ml) dissolvidos em $0,3 \mathrm{ml}$ de etanol a $30 \%$ e tratamento diário de metil jasmonato $(300 \mathrm{mg} / \mathrm{kg})$ via gavagem; $(n=5)$.

0 MeJA 95\% foi obtido da Sigma-Aldrich®. Os animais receberam enema com solução de $15 \mathrm{mg}$ de TNBS $(0,3 \mathrm{ml})$ dissolvidos em 0,3 $\mathrm{ml}$ de etanol a $30 \%$ e tratamento diário (7 dias) com $300 \mathrm{mg} / \mathrm{Kg}$ de MeJa via gavagem. Para a administração via enema nos grupos CJ e TJ foi utilizado um infusor com dois orifícios distais para melhor dispersão da substância. 0 cateter foi introduzido a aproximadamente $8 \mathrm{~cm}$ da margem anal, sendo retirado gradualmente após a instilação do MeJa.

Quanto à indução da colite experimental, os animais foram mantidos previamente em jejum alimentar de 24 horas e com livre acesso a água. Em seguida, os ratos dos grupos TN e TJ foram anestesiados com tiopental sódico na dose $40 \mathrm{mg} /$ $\mathrm{Kg}$ para receberem a aplicação de $0,6 \mathrm{ml}$ da solução contendo $0,3 \mathrm{ml}$ de TNBS (15 mg) em $0,3 \mathrm{ml}$ de etanol $30 \%$. A aplicação deu-se em dose única por meio de cateter de polietileno $\mathrm{n}^{0} 4 \mathrm{Fr}$, inserido $8 \mathrm{~cm}$ a partir do ânus (MORRIS et al., 1989), com os ratos de cabeça para baixo, suspensos pela cauda. A solução foi administrada lentamente e os animais mantidos nesta posição por mais 30 segundos após o término da 
aplicação para evitar o refluxo da solução.

Após decorridos sete dias da administração das substâncias, os animais foram eutanasiados com sobredose de tiopental sódico, totalizando $120 \mathrm{mg} / \mathrm{kg}$ e submetidos à laparotomia, com objetivo de retirar segmentos de cólon distal, direcionados para análise inflamatória e tecidual. As amostras foram lavadas em solução salina, fixadas em paraformaldeído $4 \%$ por um período de 6 horas, desidratadas em séries ascendentes de álcoois, diafanizadas em xilol, e incluídas em parafina para a obtenção de cortes histológicos transversais semi-seriados de $5 \mu \mathrm{m}$, que foram posteriormente corados pelo método de Hematoxilina \& Eosina, e utilizados para avaliar a intensidade microscópica da inflamação, a qual foi graduada semi-quantitativamente.

Para a quantificação e caracterização dos leucócitos polimorfonucleares foi realizada a contagem microscópica de 30 gânglios localizados nos gânglios nervosos mioentéricos por animal, totalizando cento $\mathrm{e}$ cinquenta gânglios por grupo. Foram utilizadas lentes objetivas com aumento de 100 vezes e ocular com aumento de 10 vezes, totalizando ampliação final de 1000 vezes, com auxílio do óleo de imersão para visualização. Tais células foram caracterizadas em: basófilos, eosinófilos, linfócitos, monócito, neutrófilo e outros, sendo este último as células consideradas inflamatórias devido às características citoplasmáticas, porém com núcleo distorcido devido aos danos causados pelo micrótomo, impedindo a sua classificação precisa junto às demais. Já a análise morfométrica das túnicas mucosa, submucosa e muscular intestinais foi feita através de amostragem de imagens capturadas em microscópio óptico Olympus® com kit para captura de imagens Axioscop 2 Plus Zeiss $\circledR$, e as espessuras das túnicas foram estimadas a partir da mensuração de 10 pontos aleatórios por corte, perfazendo 50 mensurações por animal através do sistema de análises de imagens Image Pró Plus ${ }^{\circ} 4.5$ - Media Cybernetics, Inc., com resultados expressos em $\mu \mathrm{m}$.

Para correlações estatísticas, os dados numéricos foram inicialmente submetidos ao teste Kolmogorov-Smirnov (K-S) para a verificação da normalidade. Para os dados não paramétricos foi utilizado o teste de Kruskal-Wallis seguido pelo pósteste de Dunn's. Dados paramétricos foram submetidos à Análise de Variância (one-way ANOVA) e como pósteste para comparação de médias, o teste de Tukey. Foi utilizado o software GraphPad Prism $\circledast 5$ 5.0, e os resultados expressos como média \pm desvio padrão com o nível de significância adotado de 5\%.

\section{RESULTADOS E DISCUSSÃO}

\subsection{GRADUAÇÃO DA INFLAMAÇÃO COLONICA}

A avaliação microscópica do cólon distal dos animais estáexpressanatabela 1.0sanimais dos grupos CC e CJ apresentavam morfologia intestinal padrão em todas as túnicas. Presença de criptas revestidas por epitélio simples cilíndrico e abundância de células caliciformes. Na túnica submucosa a organização das fibras de colágeno permitem a classificação deste corresponde ao tecido conjuntivo moderadamente denso, a túnica muscular externa íntegra apresentava entre as fibras musculares lisas, discreta presença de eosinófilos e com gânglios mioentéricos constituídos por corpos celulares neuronais e corpos celulares gliais. A túnica serosa apresentava-se reduzida. Sendo assim, estes grupos não apresentaram diferenças entre si na pontuação do escore $(p<0.05)$.

0 grupo TN apresentou parede intestinal parcialmente recuperada, porém especialmente no grupo TN foi possível observar a presença de infiltrado inflamatório com muitos leucócitos que avançavam em direção a mucosa e muitas vezes ocupavam totalmente a região das criptas, além de criptas distorcidas e poucos cistos e abscessos., Os gânglios mioentéricos em sua maioria apresentaram morfologia típica e discreta presença de polimorfonucleares (PMN) ao seu redor ou interior e com a serosa pouco visível. Estes resultados justificam a alta pontuação no escore, cujo valor difere dos grupos CC e CJ $(p<0.05)$. As amostras de ratos do grupo TJ também apresentaram parede intestinal parcialmente recuperada e semelhantes aos 
grupos CC e CJ $(p<0.05)$, porém com algumas regiões de erosão epiteliais na mucosa e a presença de poucos infiltrados inflamatórios. Não foram detectadas diferenças estatísticas com o grupo TN $(p<0.05)$.

Tabela 1. Graduação da inflamação colônica através de avaliação microscópica

\begin{tabular}{|c|c|c|c|c|}
\hline \multicolumn{5}{|c|}{ Escore (0-8) } \\
\hline \multicolumn{5}{|c|}{$\begin{array}{l}\text { Perda da arquitetura da mucosa } \\
\text { (0) Ausente } \\
\text { (1) Leve } \\
\text { (2) Moderada } \\
\text { (3) Severa }\end{array}$} \\
\hline \multicolumn{5}{|c|}{$\begin{array}{l}\text { Extensão do infiltrado inflamatório celular } \\
\text { (0) Ausente } \\
\text { (1) Pequena - túnica mucosa } \\
\text { (2) Média - túnica submucosa } \\
\text { (3) Intensa - transmural }\end{array}$} \\
\hline \multicolumn{5}{|c|}{$\begin{array}{l}\text { Formação de abscessos nas criptas } \\
\text { (0) Ausente } \\
\text { (1) Presente }\end{array}$} \\
\hline \multicolumn{5}{|c|}{$\begin{array}{l}\text { Intensidade e dilatação de vasos sanguíneos e presença de } \\
\text { eritrócitos } \\
\text { (0) Padrão } \\
\text { (1) Elevada }\end{array}$} \\
\hline Grupos & CC & CJ & TN & TJ \\
\hline $\begin{array}{l}\text { Média } \\
\text { EPM }\end{array}$ & $\begin{array}{l}0,72 \pm \\
0,13 \mathbf{a}\end{array}$ & $\begin{array}{c}0,97 \pm \\
0,12 \mathbf{a}\end{array}$ & $\begin{array}{l}1,73 \pm \\
0,08 \mathbf{b}\end{array}$ & $\begin{array}{c}1,35 \pm \\
0,06 \mathbf{a b}\end{array}$ \\
\hline
\end{tabular}

\subsection{QUANTIFICAÇÃO E CARACTERIZAÇÃO DE} CÉLULAS INFLAMATÓRIAS EM GÂNGLIOS NERVOSOS MIOENTÉRICOS

A relação entre os grupos e a média, por animal, da quantidade de leucócitos encontrados nos gânglios está expresso na figura 1, enquanto as diferenciações dos diferentes tipos de leucócitos em cada grupo, segundo a média por animal, estão expressos nas figuras 2 a 7 .

Pela avaliação microscópica dos fragmentos teciduais intestinais, observou-se pouco número de leucócitos totais nos animais dos grupos CC e $\mathrm{CJ}$, embora discretamente seja 0 número de focos leucocitários, os mesmos do ponto de vista clínico podem comprometer o funcionamento dos plexos mientéricos do SNE, devido a intima relação com a imunidade intestinal (GEBOES, COLLINS, 1998); não houve diferença estatística $(p<0,05)$ entre tais grupos. Além disso, nestes grupos, os gânglios apresentavamse com tamanho padrão, sem alterações estruturais ou presença de lesões. Já nos animais do grupo TN, houve aumento significativo na média de leucócitos totais por animal em gânglios, com diferença estatística em comparação aos demais grupos $(p>0,05)$, visto as características de infiltrado inflamatório no SNE e a dilatação dos gânglios nas DIls (GEBOES, COLLINS, 1998), indicando mimetização do modelo experimento induzido pelo TNBS. Em contrapartida, o grupo $\mathrm{TJ}$, representado os animais tratados com MeJA, apresentou redução do número de leucócitos totais em gânglios, tendo relação estatística com os grupos CC e CJ $(p<0,05)$, diferenciando-se do grupo TN $(p>0,05)$, mostrando a sua capacidade anti-inflamatória (DANG et al., 2008). (Figura 1).

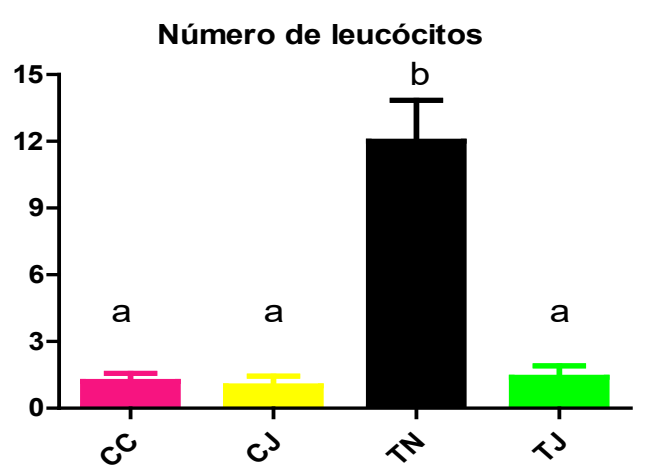

Figura 1. Quantidade média de leucócitos em gânglios mioentéricos por animal por grupo.

Em relação aos linfócitos, observamos nos grupos CC e CJ houve quantidade reduzida, não havendo diferença estatística entre esses grupos $(p<0,05)$. Quanto ao TN, observou-se aumento estatístico $(p>0,05)$ na média de linfócitos por animal, indicando um mecanismo direto de resposta imune adaptativa, com produção em grande escala de imunoglobulinas (FIOCCHI, 1998; SANCHEZ-MUÑOZ, DOMINGUEZ-LOPEZ, YAMAMOTO-FURUSHO, 2008). No TJ, notou-se a redução da média de linfócitos por animal, chegando ao nível estatístico dos grupos CC e CJ $(p<0,05)$, também se diferenciando de TN $(p>0,05)$. (Figura 2). 


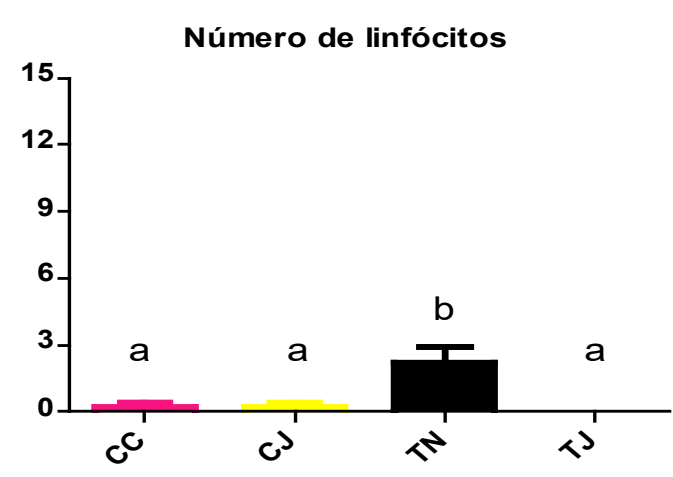

Figura 2. Quantidade média de linfócitos em gânglios mioentéricos por animal por grupo.

Referente aos monócitos infiltrados em gânglios, CC e CJ continham quantidades reduzidas assim como ocorrido aos linfócitos, apresentando semelhança estatística $(p<0,05)$. Enquanto 0 grupo TN apresentou aumento na média da quantidade de monócitos em gânglios, tendo diferença em relação aos demais grupos ( $p>0,05)$, também devido ao seu envolvimento na DII (FIOCCHI, 1998; SANCHEZ-MUÑOZ, DOMINGUEZ-LOPEZ, YAMAMOTO-FURUSHO, 2008). Já 0 grupo TJ apresentou menores quantidades-no infiltrado de monócitos, sendo semelhante estatística com grupo CC e CJ, indicando mais uma vez 0 efeito anti-inflamatório do MeJA. (Figura 3).

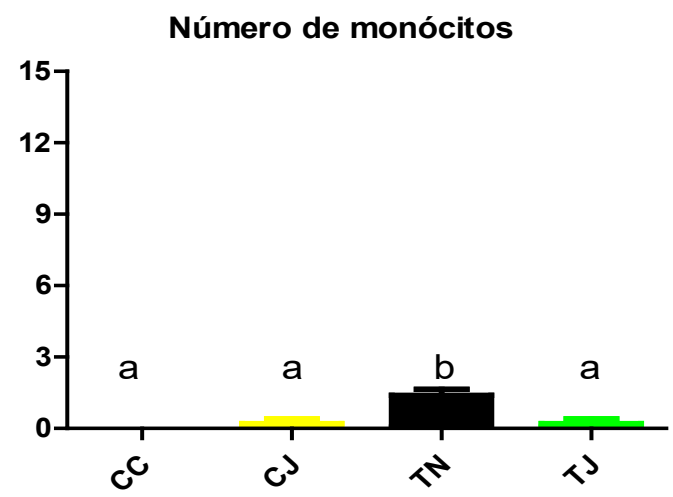

Figura 3. Quantidade média de monócitos em em gânglios mioentéricos por animal por grupo.

$\mathrm{Na}$ caracterização às chamadas "outras" células, foram incluídas como aqueles que apresentavam citoplasma basófilo e núcleo com morfologia, impedindo sua classificação de acordo com os diferentes perfis celulares descritos anteriormente. Estatisticamente os grupos CC e CJ não diferiram $(p<0,05)$, enquanto que no grupo TN houve aumento $(p>0,05)$ do infiltrado inflamatório ganglionar. Já no grupo TJ, houve redução da média de tais células por animal, equiparando-se mais uma vez à quantidade dos grupos CC e CJ $(p<0,05)$, e inclusive diferindo do grupo TN $(p>0,05)$. (Figura 4).

\section{Número de outras células}

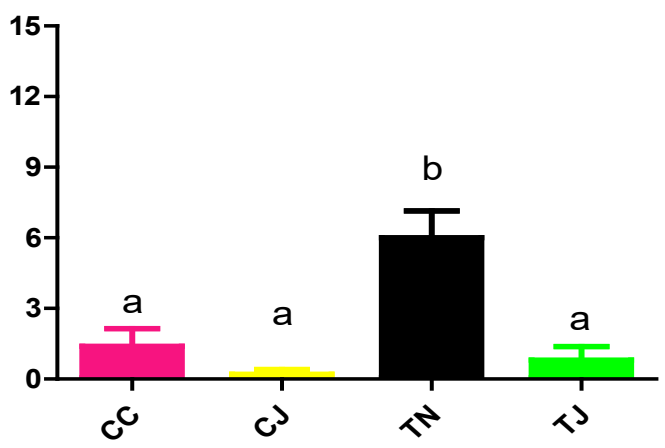

Figura 4. Quantidade média de "outras células" em em gânglios mioentéricos por animal por grupo.

Quanto aos demais leucócitos, não foram encontradas alterações estatísticas $(p<0,05)$ entre as médias de eosinófilos e neutrófilos nos diferentes grupos avaliados (Figuras 5 e 6, respectivamente). Porém, neste estudo, os basófilos apresentaram resultados diferentes dos demais grupos leucocitários, visto que 0 grupo CJ apresentou aumento na média celular em relação ao grupo CC; 0 grupo TN apresentou a maior média do número de células enquanto 0 TJ apresentou média semelhante estatisticamente ao grupo CC $(p<0,05)$ e redução em relação à TN (Figuras 7). Os resultados não justificam, para 0 grupo $\mathrm{CJ}$, tratado somente com MeJA e solução salina, quanto ao aumento na média de basófilos em relação ao grupo controle, sendo necessários estudos moleculares para avaliar a relação do composto com a dinâmica de ativação imune desta linhagem celular. 


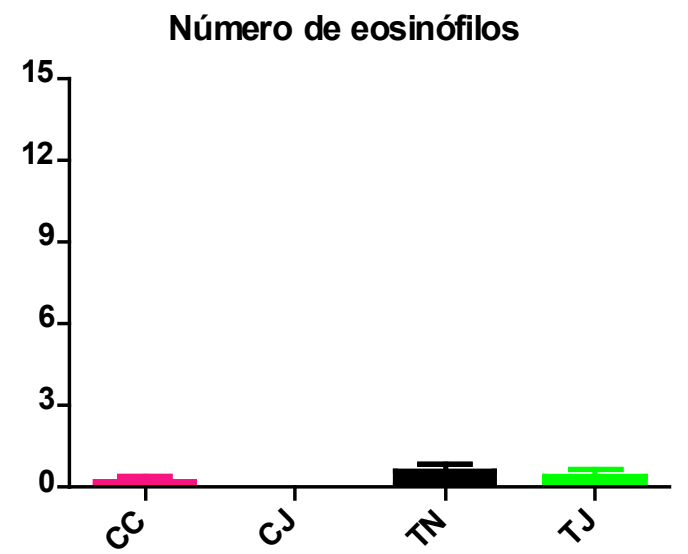

Figura 5. Quantidade média de eosinófilos em gânglios mioentéricos por animal por grupo.

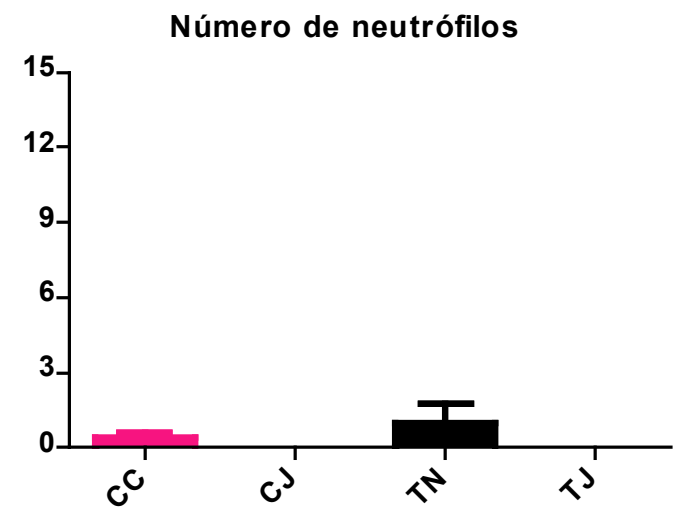

Figura 6. Quantidade média de neutrófilos em gânglios mioentéricos por animal por grupo.

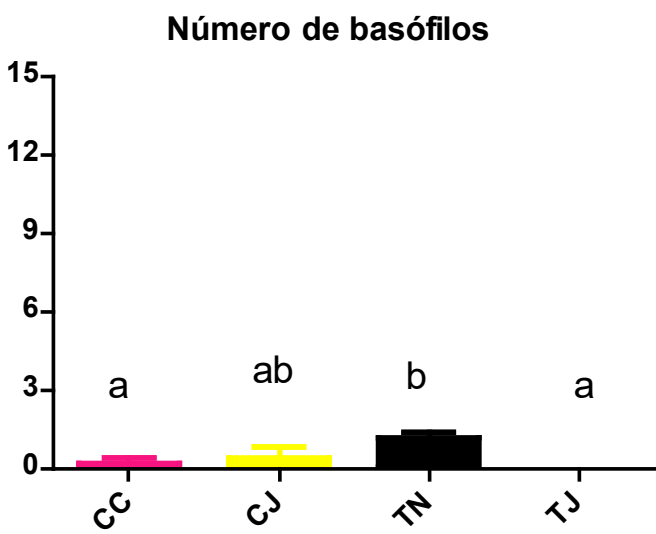

Figura 7. Quantidade média de basófilos em plexos mioentéricos por animal por grupo.

Fonte: Dados da pesquisa
3.3 ANÁLISE MORFOMÉTRICA DAS TÚNICAS INTESTINAIS

Os resultados relativos à análise das túnicas intestinais foram expressos em micrômetros quadrados $(\mu \mathrm{m})$, em média de medidas de cada túnica, divididas entre os grupos experimentais, onde os resultados foram expressos em figuras.

A figura oito demonstra os resultados obtidos em relação à camada mucosa intestinal, sendo que esta não diferiu estatisticamente entre os grupos avaliados $(p<0,05)$. No grupo tratado com TNBS, embora estudos feitos por Isik et al. (2010) demonstrem efeitos lesão celular de camada mucosa, elucida-se que, devido à analise ser referente à efeitos cronificados da doença induzida, houve recuperação parcial autógena nos animais do grupo. Enquanto os demais grupos mantiveram-se com valores também semelhantes aos controle.

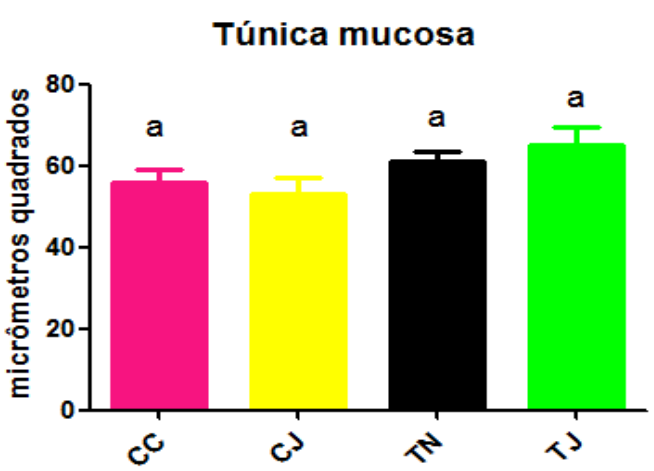

Figura 8. Espessura média, em micrômetros de túnica mucosa por animal por grupo.

Quanto à túnica submucosa, expressa na figura nove, revelou diferença estatística entre os grupos avaliados. Os grupos controle e CJ obtiveram médias relacionadas estatisticamente entre si $(p<0,05)$, enquanto TN apresentou aumento na média e diferiu-se dos demais grupos ( $p>0,05$ ), fato esse que atribui-se pela característica da DII, onde espera-se a ocorrência de edema submucoso devido à inflamação causada pelo TNBS (ISIK et al., 2010). Enquanto 0 grupo tratado com MeJA apresentou-se com média morfométrica semelhante às dos CC e CJ, como consequência de seu efeito anti-inflamatório, onde, 
devido à diminuição de citocinas pró-inflamatórias, houve diminuição do edema (DANG et al., 2008).

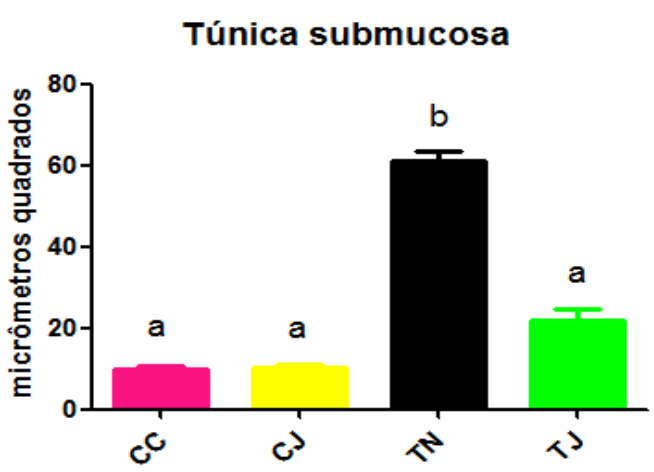

Figura 9. Espessura média, em micrômetros, de túnica submucosa por animal por grupo.

Já as medidas relacionadas à muscular estão expressas na figura dez. Os grupos CC e CJ apresentaram semelhança estatística com TN e TJ $(p<0,05)$, enquanto TJ caracterizou-se como 0 único grupo experimental com diferenciação estatística de TN ( $p>0,05)$. 0 espessamento da camada muscular no grupo tratado com TNBS já havia sido previamente relatado por Moreels et al. (2001), onde a diferença em comparação ao grupo TJ está relacionada, da mesma forma, com a capacidade anti-inflamatória do MeJA (DANG et al., 2008), que reduz os efeitos danosos do TNBS sobre 0 tecido.

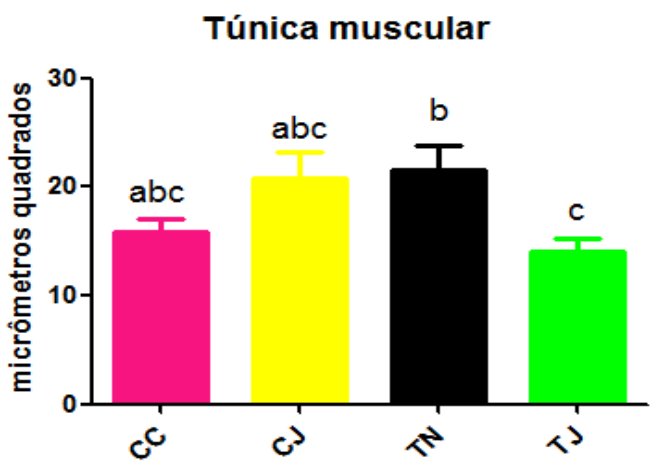

Figura 10. Espessura média, em micrômetros, de túnica muscular por animal por grupo.

\section{CONCLUSÃO}

0 tratamento das Dlls merece atenção, pois se trata de um problema de saúde pública em ascensão nas populações mundiais, e também pelo fato de os tratamentos convencionais apresentarem efeitos colaterais diversos e destas doenças não apresentarem cura. Portanto, com base nesta pesquisa constatamos que 0 MeJA representa um novo alvo farmacológico, mostrando-se eficaz para 0 tratamento dessas doenças, devido a sua capacidade anti-neuroinflamatória intestinal por ação no sistema nervoso entérico, e também pela capacidade de reparo tecidual, principalmente de camada submucosa intestinal.

\section{REFERÊNCIAS}

ARAB, H. H. et al. Camel's milk ameliorates TNBSinduced colitis in rats via downregulation of inflammatory cytokines and oxidative stress. Food and Chemical Toxicology, v. 69, p.294-302, jul. 2014.

ARDITE, E. et al. Replenishment of Glutathione Levels Improves Mucosal Function in Experimental Acute Colitis. Laboratory Investigation, v. 80, n. 5, p.735744, maio 2000.

DANG, H. T. et al. New jasmonate analogues as potential anti-inflammatory agents. Bioorganic \& Medicinal Chemistry, v. 16, n. 24, p.10228-10235, 15 dez. 2008.

DOST, T. et al. The Effect of Hypericum perforatum (St. John's Wort) on Experimental Colitis in Rat. Digestive Diseases and Sciences, v. 54, n. 6, p.1214-1221, 27 ago. 2008.

EREJUWA, 0. 0.; SULAIMAN, S. A.; WAHAB, M. S. A. Honey: a novel antioxidant. Molecules, v. 17, n. 4, p. 4400-4423, abr. 2012.

ESMAILY, H. et al. On the benefits of silymarin in murine colitis by improving balance of destructive 
cytokines and reduction of toxic stress in the bowel cells. Open Life Sciences, v. 4, n. 2, p. 204-213, jan. 2009.

FAR00QI, A. A.; BUTT, G.; RAZZAQ, Z. Algae extracts and methyl jasmonate anti-cancer activities in prostate cancer: choreographers of 'the dance macabre'. Cancer Cell International, v. 12, n. 1, p. 50-56, 2012.

FINGRUT, 0; FLESCHER, E. Plant stress hormones suppress the proliferation and induce apoptosis in human cancer cells. Leukemia, v. 16, n. 4, p. 608616, abr. 2002.

FINGRUT, 0. et al. Jasmonates induce nonapoptotic death in high-resistance mutant p53expressing B-lymphoma cells. British Journal of Pharmacology, v. 146, n. 6, p. 800-808, nov. 2005.

FIOCCHI, C. Inflammatory bowel disease: etiology and pathogenesis. Gastroenterology, v. 115, n. 1, p. 182-205, 1998.

GEBOES, K.; COLLINS, S. Structural abnormalities of the nervous system in Crohn's disease and ulcerative colitis. Neurogastroenterol Motil, v. 10, n. 3, p. 189202, 1998.

GOLD, D. et al. The Antiparasitic Actions of Plant Jasmonates. Journal of Parasitology, v. 89, n. 6, p. 1242-1244, dez. 2003.

HANSEN, M. B. The Enteric Nervous System I: Organisation and Classification. Pharmacology and Toxicology, v. 92, n. 3, p. 105-113, mar. 2003.

HARTMANN, R. M. et al. Effect of Boswellia serrata on Antioxidant Status in an Experimental Model of Colitis Rats Induced by Acetic Acid. Digestive Diseases and Sciences, v. 57, n. 8, p. 2038-2044, 27 mar. 2012. Springer Nature.

ISIK, F. et al. Protective Effects of Black Cumin (Nigella sativa) Oil on TNBS-Induced Experimental Colitis in Rats. Digestive Diseases and Sciences, v. 56, n. 3, p. 721-730, 24 jul. 2010.
KANDHARE, A. D. et al. Effect of hydroalcoholic extract of Hibiscus rosa sinensis Linn. leaves in experimental colitis in rats. Asian Pacific Journal of Tropical Biomedicine, v. 2, n. 5, p. 337-344, maio 2012.

KRISHNAN, M. et al. Antioxidant mediated antiulcer effect of Eupatorium triplinerve Vahl against acetic acid induced ulcerative colitis in mice. Biomedicine \& Aging Pathology, v. 4, n. 2, p. 153-160, abr. 2014.

LIU, X.; WANG, J. Anti-inflammatory effects of iridoid glycosides fraction of Folium syringae leaves on TNBS-induced colitis in rats. Journal of Ethnopharmacology, v. 133, n. 2, p. 780-787, jan. 2011.

MARTín, A. R. et al. Resveratrol, a polyphenol found in grapes, suppresses oxidative damage and stimulates apoptosis during early colonic inflammation in rats. Biochemical Pharmacology, v. 67, n. 7, p. 1399-1410, abr. 2004.

MOREELS, T. G. et al. Effect of TNBS-induced morphological changes on pharmacological contractility of the rat ileum. European Journal of Pharmacology, v. 423, n. 2-3, p. 211-222, jul. 2001.

MORRIS, G. P. et al. Hapten-induced model of chronic inflammation and ulceration in the rat colon. Gastroenterology, v. 96, n. 3, p. 795-803, 1989.

MOURA, F. A. et al. Antioxidant therapy for treatment of inflammatory bowel disease: Does it work? Redox Biology, v. 6, p. 617-639, dez. 2015.

OFER, K.; GOLD, D.; FLESCHER, E. Methyl jasmonate induces cell cycle block and cell death in the amitochondriate parasite Trichomonas vaginalis. International Journal for Parasitology, v. 38, n. 8-9, p. 959-968, jul. 2008.

SANCHEZ-MUÑOZ, F.; DOMINGUEZ-LOPEZ, A.; YAMAMOTO-FURUSHO, J. K. Role of cytokines in inflammatory bowel disease. World Journal of Gastroenterology, v. 14, n. 27, p. 4280-4288, 2008.

SANTOS, M. S. N. et al. Effect of Glucans from 
Caripia montagnei Mushroom on TNBS-Induced Colitis. International Journal of Molecular

Sciences, v. 15, n. 2, p. 2368-2385, fev. 2014.

SERIL, D. N. Oxidative stress and ulcerative colitisassociated carcinogenesis: studies in humans and animal models. Carcinogenesis, v. 24, n. 3, p. 353362, 2003.

UMUKORO, S.; OLUGBEMIDE, A. S.. Antinociceptive effects of methyl jasmonate in experimental animals. Journal of Natural Medicines, v. 65, $\mathrm{n}$. 3-4, p. 466-470, mar. 2011.

WANG, S.; BOWMAN, L.; DING, M. Methyl jasmonate enhances antioxidant activity and flavonoid content in blackberries (Rubus sp.) and promotes antiproliferation of human cancer cells. Food Chemistry, p. 1261-1269, out. 2007.

Recebido em:07/08/2019

Aceito em: 30/10/2019 